\title{
LIPID PEROXIDATION IN MULTIPLE ORGAN FAILURE CAUSED BY ASSOCIATED CHEST AND HIP TRAUMA
}

\author{
M. I. Marushchak, M. M. Khudobiak, I. Ya. Krynytska, I. V. Antonyshyn \\ I. HORBACHEVSKY TERNOPIL STATE MEDICAL UNIVERSITY, TERNOPIL, UKRAINE
}

Background. The injured with polytrauma are classified as extremely severe patients, as their emergency care and intensive care is followed by significant difficulties, frequent development of complications, high mortality and survivors disability.

Objective. This study is aimed to evaluate the effect of lipid peroxidation in heart, lungs, liver and blood of rats in early and late periods of combined traumatic injury of chest and hips and to establish their influence on the development of multiple organ failure.

Methods. The study was conducted on 70 adult male white nonlinear rats. It was determined the content of lipid hydroperoxides and concentration of TBA-active products in erythrocyte mass, heart, lungs and liver.

Results. The data prove activation of free radical oxidation at the first day of post-traumatic period. Analysis of the data evidences the increase in of lipid hydroperoxides (HPL) rate in liver homogenate in group E1 in 1.5 times, in all subsequent periods of the research the increase in rate fluctuated within 1.9-2.0 times. In blood and heart the HPL rate increased twice in group E1, reached maximum in group E2 and gradually decreased till the end of the experiment, data exceeded the control group. The highest level of HPL was determined in lung tissues $(r \leq 0.01)$. In the post traumatic period the highest TBA-AP was detected in lungs and liver.

Conclusions. In case of simulated trauma (injury of chest with fractures of both hips) hyperactivation processes of free radical oxidation is observed in 1 day, reaching a peak in 7-14 days of post-traumatic period in blood, tissues, liver, heart and lungs if compared to the control group causing multiple organ failure.

KEY WORDS: trauma, lipid peroxidation, lung, liver, heart.

\section{Introduction}

Nowadays one of the most urgent problems of medicine are multiple and combined injuries $[1,2]$. This is due to the constant increase of the number of multisystem and multiorgan injuries on the background of some general manifestations of injuries stabilization, which leads to mortality increase $[3,4]$. As a result of constant technological advances the increase in the number of man-made disasters has led to a significant increase in the number of patients with polytrauma. According to WHO trauma is one of the top five causes of death among people aged 15-44; mortality from injuries and accidents takes the first place [5]. The injurees with polytrauma are classified as extremely severe patients, as emergency care and intensive care is accompanied by significant diffi-

Corresponding author: Marya Marushchak, Department of Functional Diagnostics and Clinical Pathophysiology, I. Horbachevsky Ternopil State Medical University, 1 Maidan Voli, Ternopil, Ukraine, 46001

Phone number: +380979901202

E-mail: marushchak@tdmu.edu.ua culties, frequent development of complications, high mortality and survivors' disability [6]. In case of multiple trauma, wounded are primarily affected by phenomena of traumatic-haemorrhagic shock and tissue hypoxia. In the posttraumatic period unnoticed injuries, infection, SIRS, sepsis and multiple organ failure threaten their life and health [7].

Therefore, our study was aimed to evaluate the effect of lipid peroxidation in heart, lungs, liver and blood of rats in early and late periods of combined traumatic injury of chest and hips and establish their influence on the development of multiple organ failure.

\section{Material and Methods}

The study was conducted on 70 adult male white nonlinear rats of 200-220 g body weight. Rats were housed under standardized laboratory conditions, with $12 \mathrm{~h}$ dark/light cycle and free access to food and tab water ad libitum. All procedures were conducted according to the European Convention for the Protection of 
Vertebrate Animals used for Experimental and Other Scientific Purposes (Strasbourg, 1986) and General Ethical Principles of Experiments using Animals (First National Congress of Bioethics, Kyiv, 2001). The animals were randomly divided into 8 groups: 1 control (C1) and 5 experimental (E1, E2, E3, E4, E5) groups, each comprising 12 animals. Rats of experimental groups. The animals in the experimental group underwent thiopental sodium anaesthesia (40 mg/kg intraperitoneal rat) using a trocar modeled right-closed pneumothorax from fractured ribs and combined them with a broken left and right femur. Skeletal injury was modeled by applying a single shock dosed by a specially designed device on each thigh, which caused a closed fracture [8]. Impact energy was $0.375 \mathrm{~J}$, which corresponded to the injury of moderate severity. Combined injury was modeled by sequential administration of these two injuries. Mortality of animals in each group was E1(12/11), E2(12/9), E3(12/10), E4(12/10), $E 5(12 / 9)$. At the end of the experimental period, the rats were sacrificed by decapitation.

The content of lipid hydroperoxides in erythrocyte mass, heart, lungs and liver was determined by [9]. This method is based on spectrophotometrical optical density measurement of the products of ammonium thiocyanate, hydrochloric acid and Mohr salt reaction. Lipids from the samples were preliminarily extracted with ethanol. Selection of tissue samples and preparation for extraction were performed at $4^{\circ} \mathrm{C}$. Ethanol $(2.8 \mathrm{ml})$ and $0.05 \mathrm{ml}$ of $50 \%$ trichloroacetic acid (TCA) were added to $0.2 \mathrm{ml}$ of hemolisate (dissolved in buffer solution with $\mathrm{pH} 7.4$ ), and shaken for 5-6 min. Obtained protein precipitate was separated by centrifugation at $700 \mathrm{~g}$. Ethanol $(1.2 \mathrm{ml}), 0.02 \mathrm{ml}$ of concentrated $\mathrm{HCl}$, and $0.03 \mathrm{ml}$ of $1 \% \mathrm{Mohr}$ salt solution in $3 \% \mathrm{HCl}$ were added to $1.5 \mathrm{ml}$ of supernatant. The mixture was stirred. After $30 \mathrm{~s}, 0.2 \mathrm{ml}$ of $20 \%$ ammonium thiocyanate was added, and then the absorbance of the solution was determined at $\lambda=480 \mathrm{~nm}$. In a control sample, the appropriate amount of bidistilled water was added instead of supernatant. The content of lipid hydroperoxides was calculated by the difference between experimental and control values, and expressed in arbitrary units of optical density for $1 \mathrm{mg}$ of protein.

The concentration of TBA-active products, characterizing the LPO rate, was assessed by Korobeinikova method based on the reaction between malondialdehyde (MDA) together with other products of peroxidation and thiobarbituric acid (TBA), occurring at high temperature and in acidic environment, and forming the colored complex of one MDA and two TBA molecules [10]. Protein concentration was measured by Lowry [11]. All reagents used were obtained from SigmaAldrich and Fluka (USA). The experimental data were processed by variation statistics methods by the OriginPro 8 program. Student t-test was used to determine the likely differences between the means of the samples. In all cases, reliable differences were considered by $\mathrm{P}$ value under $5 \%(\mathrm{P}<0.05)$.

\section{Results and Discussion}

The data prove activation of free radical oxidation at the first day of post-traumatic period (Table 1 and 2). Activation of peroxide oxidation is one of the factors destabilizing membrane [12]. It is established that the action of hydroxyl radicals in diene conjugates fatty acids, lipid hydroperoxide is formed, which cause conformational irregularities in cell mem-

Table 1. The rates of lipid hydroperoxides in rat tissues (cu/mg protein) after combined trauma of chest and both hips $(\mathrm{M} \pm \mathrm{m})$

\begin{tabular}{|l|c|c|c|c|}
\hline \multicolumn{1}{|c|}{ Animal group } & Blood & Heart & Lungs & Liver \\
\hline Control & $0.98 \pm 0.05$ & $0.83 \pm 0.02$ & $0.63 \pm 0.02$ & $0.83 \pm 0.02$ \\
\hline $\begin{array}{l}\text { Trauma of chest and hips, } \\
1^{\text {st }} \text { day of observation }\end{array}$ & $\begin{array}{c}1.96 \pm 0.01 * \\
\mathrm{p} \leq 0.01\end{array}$ & $\begin{array}{c}1.64 \pm 0.02 * \\
\mathrm{p} \leq 0.01\end{array}$ & $\begin{array}{c}1.62 \pm 0.01 * \\
\mathrm{p} \leq 0.01\end{array}$ & $\begin{array}{c}1.26 \pm 0.01 * \\
\mathrm{p} \leq 0.05\end{array}$ \\
\hline Trauma of chest and hips, & $2.36 \pm 0.08 *$ & $2.20 \pm 0.07 *$ & $1.79 \pm 0.01 *$ & $1.58 \pm 0.02 *$ \\
$3^{\text {rd }}$ day of observation & $\mathrm{p} \leq 0.05$ & $\mathrm{p} \leq 0.01$ & $\mathrm{p} \geq 0.05$ & $\mathrm{p} \leq 0.01$ \\
\hline Trauma of chest and hips, & $2.03 \pm 0.06 *$ & $1.82 \pm 0.01 *$ & $2.04 \pm 0.05^{*}$ & $1.80 \pm 0.01^{*}$ \\
$7^{\text {th }}$ day of observation & $\mathrm{p} \leq 0.01$ & - & $\mathrm{p} \leq 0.01$ & $\mathrm{p} \leq 0.01$ \\
\hline Trauma of chest and hips, & $1.88 \pm 0.06 *$ & $1.78 \pm 0.02 *$ & $1.85 \pm 0.01 *$ & $1,65 \pm 0.01 *$ \\
$14^{\text {th }}$ day of observation & - & - & $\mathrm{p} \leq 0,01$ & $\mathrm{p} \leq 0,05$ \\
\hline Trauma of chest and hips, & $1.71 \pm 0.04 *$ & $1.62 \pm 0.04 *$ & $1.62 \pm 0.01 *$ & $1.57 \pm 0.02 *$ \\
$28^{\text {th }}$ day of observation & - & - & $\mathrm{p} \leq 0.01$ & $\mathrm{p} \leq 0,01$ \\
\hline
\end{tabular}

Notes. Tables 1 and 2: * — significant differences between the baseline indicators of the studied and control groups; $\mathrm{p}$ - significant differences between the experimental groups. 
Table 2. The rate of active products of thiobarbituric acid in rat tissues ( $\mathrm{mmol} / \mathrm{mg}$ protein) after combined trauma of chest and both hips $(\mathrm{M} \pm \mathrm{m})$

\begin{tabular}{|l|c|c|c|c|}
\hline \multicolumn{1}{|c|}{ Animal group } & Blood & Heart & Lungs & Liver \\
\hline Control & $0.22 \pm 0.01$ & $0.36 \pm 0.01$ & $0.20 \pm 0.08$ & $0.40 \pm 0.02$ \\
\hline Trauma of chest and hips, & $0.40 \pm 0.01$ & $0.70 \pm 0.02 *$ & $0.42 \pm 0.02$ & $0.87 \pm 0.02^{*}$ \\
$1^{\text {st }}$ day of observation & $\mathrm{p} \geq 0.05$ & $\mathrm{p} \leq 0.01$ & $\mathrm{p} \geq 0.05$ & $\mathrm{p} \leq 0.01$ \\
\hline Trauma of chest and hips, & $0.75 \pm 0.02^{*}$ & $0.97 \pm 0.03^{*}$ & $0.68 \pm 0.02^{*}$ & $1.23 \pm 0.02^{*}$ \\
$3^{\text {rd }}$ day of observation & $\mathrm{p} \leq 0.05$ & $\mathrm{p} \leq 0.01$ & $\mathrm{p} \leq 0.01$ & $\mathrm{p} \leq 0.01$ \\
\hline Trauma of chest and hips, & $1.06 \pm 0.03^{*}$ & $0.80 \pm 0.02^{*}$ & $0.67 \pm 0.01 *$ & $1.76 \pm 0.03^{*}$ \\
$7^{\text {th }}$ day of observation & $\mathrm{p} \leq 0.01$ & $\mathrm{p} \geq 0.05$ & $\mathrm{p} \geq 0.05$ & $\mathrm{p} \leq 0.01$ \\
\hline Trauma of chest and hips, & $0.86 \pm 0.02^{*}$ & $0.75 \pm 0.02^{*}$ & $0.60 \pm 0.02 *$ & $2.08 \pm 0.04^{*}$ \\
$14^{\text {th }}$ day of observation & $\mathrm{p} \leq 0.01$ & $\mathrm{p} \geq 0.05$ & $\mathrm{p} \leq 0.01$ & $\mathrm{p} \leq 0.05$ \\
\hline Trauma of chest and hips, & $0.72 \pm 0.03^{*}$ & $0.68 \pm 0.03^{*}$ & $0.53 \pm 0.02 *$ & $1.87 \pm 0.02^{*}$ \\
28 $^{\text {th }}$ day of observation & $\mathrm{p} \geq 0.05$ & $\mathrm{p} \geq 0.05$ & $\mathrm{p} \geq 0.05$ & $\mathrm{p} \geq 0.05$ \\
\hline
\end{tabular}

branes. Analysis of the data evidences the increase in HPL rate in liver homogenate in group E1 in 1.5 times, in all subsequent periods of observation the increased rate fluctuated within 1.9-2.0 times. In blood and heart the HPL rate increased twice in group E1, reached a maximum in group E2, and gradually decreased until the end of the experiment, data exceeded the control group (Table 1). The highest level of HPL was determined in lung tissues, particularly in $\mathrm{E} 1$ it exceeded in 2.6 times the control rate, respectively E2 - in 2.9 times, E3 - in 3.2 times, E4 - in 3.0 times and E5 - in 2.5 times $(r \leq 0.01)$. Due to the fact that in case of trauma in lung tissues the activation of neutrophils is the main source of reactive oxygen species [13], and taking into account the administered chest injury, we believe that the pathological processes that occur in lungs in case of simulated injuries have a significant contribution to the development of multiple organ failure.

It is established that fatty acids in the ground connection break into fragments of aldehyde groups at the ends to form malonic dialdehyde. Analysing the change of active products thiobarbituric acid in rat tissues, different activity of lipid peroxidation in the studied rat organs was revealed (Table 2). The post traumatic period following combined chest trauma of both thighs on the $1^{\text {st }}$ day surveillance the highest TBA-AP was detected in lungs and liver, respectively, in 3 days - in blood and lungs, in 7 days and in subsequent periods of observation - in blood and liver (Table 2).

For a comparative analysis of the flow of free radical oxidation in various organs combined chest trauma of both thighs was administered, the control group was regarded as $100 \%$. It is established that the phenomenon of lipid peroxidation in heart was the most intense on the $3^{\text {rd }}$ day after polytrauma simulation, respectively, in lungs - from the $3^{\text {rd }}$ to the $7^{\text {th }}$ day, in blood - on the $7^{\text {th }}$ day, in liver - on the $14^{\text {th }}$ day (Fig. 1). Scientists have proved that the maximum intensity of lipid peroxidation coincides with the body's response to inflammation

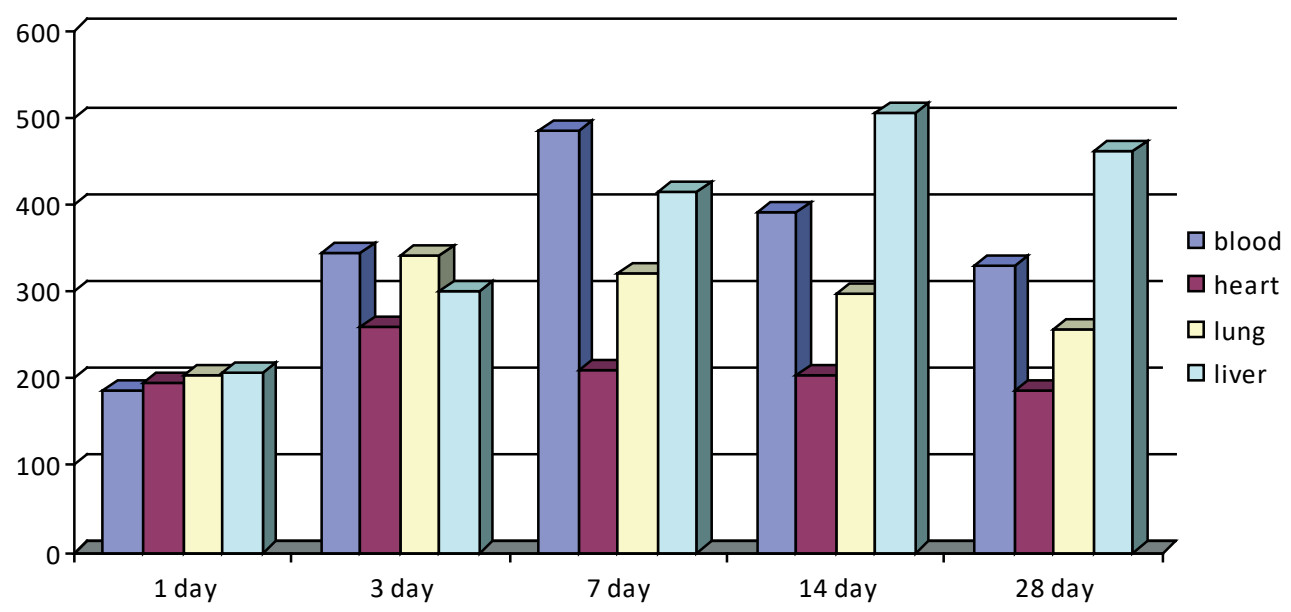

Fig. 1. Severity of the processes of lipid peroxidation (\%) in rat tissues (as example, MDA-AP) in post-traumatic period following combined trauma of chest and both hips. 
[14]. The development of hypoxemia caused by chest trauma affected lipid peroxidation stimulation causing disruption of cell membranes structure and consequently cell death closing the 'vicious' circle, which in our and other authors opinion cause multiple organ failure with involvement of heart, lungs, liver in the pathological process [15].

The data indicate that the intensity of lipid peroxidation in different tissues of body depends on injury type. Thus, Kozak D.V. in the research [16] notes that the intensity of lipid peroxidation due to blood loss and hip trauma has oscillatory nature of the duration increase up to the third day, the period of temporary welfare in 14 days and repeated increase in 21

\section{References}

1. Guriev SA, Tanasienko PV, Satsyk SP. Clinical and epidemiological characteristics of patients with infectious complications of trauma due to accidents. Medicine today and tomorrow 2012; 1: 54.

2. Gao JM, Gao YH, Zeng JB, Wang JB. Polytrauma with thoracic and / or abdominal injuries: experience in 1540 cases. J. Traumatol 2006; 9: 108-114.

3. WHO. Trauma Care Checklist [electronic resource]. - Access: http://www.whp.int/patientsafety/implementation/checlists/trauma/en/index. html.

4. Aghajanian VV, Ustyantseva IM, Pronskiy AA. Polytrauma. Emergency care and transportation. Novosibirsk: Nauka 2008; 320.

5. Malysh IR, Dvorskyy PD, Zhrzheblovskaya LV, Krylyuk VA. The strategy of empirical antibiotic therapy in patients with severe polytrauma. Materials of All-Ukrainian scientific-practical conference with international participation. Zaporizhzhia 2010; 95-97.

6. Tsybulyak GN. Treatment of severe damage. St. Petersburg: Hyppokrat 1995; 424.

7. Adams HA, Trenz O. Uter Mitarbeit der IAG Schock der DIVI. Anaesthesieologie und Intensiv medizin 2007; 73-97.

8. Prydruha SM, Borys RM. A violation of the humoral component of immunity during the period of late manifestations of wound dystrophy and its correction by thiotriazoline. Bukovyn. Med. Visn 2013; 17 (1): 96-101.

9. Vlizlo VV, Fedoruk RS, Ratych IB. Laboratory methods of research in biology, animal husbandry and veterinary medicine. Lviv: Spolom 2012; 764. (In Ukrainian). days. Our results prove that various tissues experience peroxidation activation and its maximum occurs at different time.

\section{Conclusions}

In case of simulated trauma (chest injury with fractures of both hips) hyperactivation processes of free radical oxidation is observed in the $1^{\text {st }}$ day, reaching a peak in $7-14^{\text {th }}$ days of post-traumatic period in blood, tissues, liver, heart and lungs if compared to the control group that causes multiple organ failure.

The future prospects of the research are investigation of oxidant system dynamics after traumatic injuries of chest and hips and establishment of antioxidant-prooxidant disbalance.
10. Korobeynikova E. A modification of lipid peroxidation products assessment in the reaction with thiobarbituric acid. Lab. delo 1989; (7): 8-9. (In Russian).

11. Lowry OH, Rosebrough NJ, Farr AL, Randall RJ. Protein measurement with the Folin VP Rosalovsky, SV Grabovska, YuT Salyha 132 ISSN 2409-4943. Ukr. Biochem. J., 2015, Vol. 87, N 5 phenol reagent. J. Biol. Chem 1951; 193 (1): 265-275.

12. Marushchak M, Krynytska I, Petrenko N, Klishch I. The determination of correlation linkages between level of reactive oxygen species, contents of neutrophiles and blood gas composition in experimental acute lung injury. Georgian medical news 2016; 253: 98-103.

13. Dushianthan A, Grocott MP, Postle AD, Cusack R. Acute respiratory distress syndrome and acute lung injury. Postgrad. Med. J. 2011; 87(1031): 612-622.

14. Henynh TP, Kseyko DA. Indicator peroxide oxidation and antioxidant protection lipids in the system 'blood sera - erythrocytes "in acute circulation hypoxi.a Success of modern natural science 2004; 4: 17-20.

15. Malysh IR, Kozlov VK, Zhrzheblovskaya LV. Profile of cyrculating cytokines and their mononuclear production in dynamics in post traumatical period injuired with polytrauma. Cytokines and Inflammation 2007; I 6 (3): 49-56.

16. Kozak D. Features indices of lipid peroxidation in the dynamics of early and late periods of trauma. Actual problems of emergency 2012; 3 (29): 103-106.

Received: 2016-12-10 